Document downloaded from:

http://hdl.handle.net/10251/100070

This paper must be cited as:

Abad Fuentes, S.; Vayá Pérez, I.; Jiménez Molero, MC.; Pischel ., U.; Miranda Alonso, MÁ. (2006). Diastereodifferentiation of novel naphthalene dyads by fluorescence quenching and excimer formation. ChemPhysChem. 7(10):2175-2183. doi:10.1002/cphc.200600337

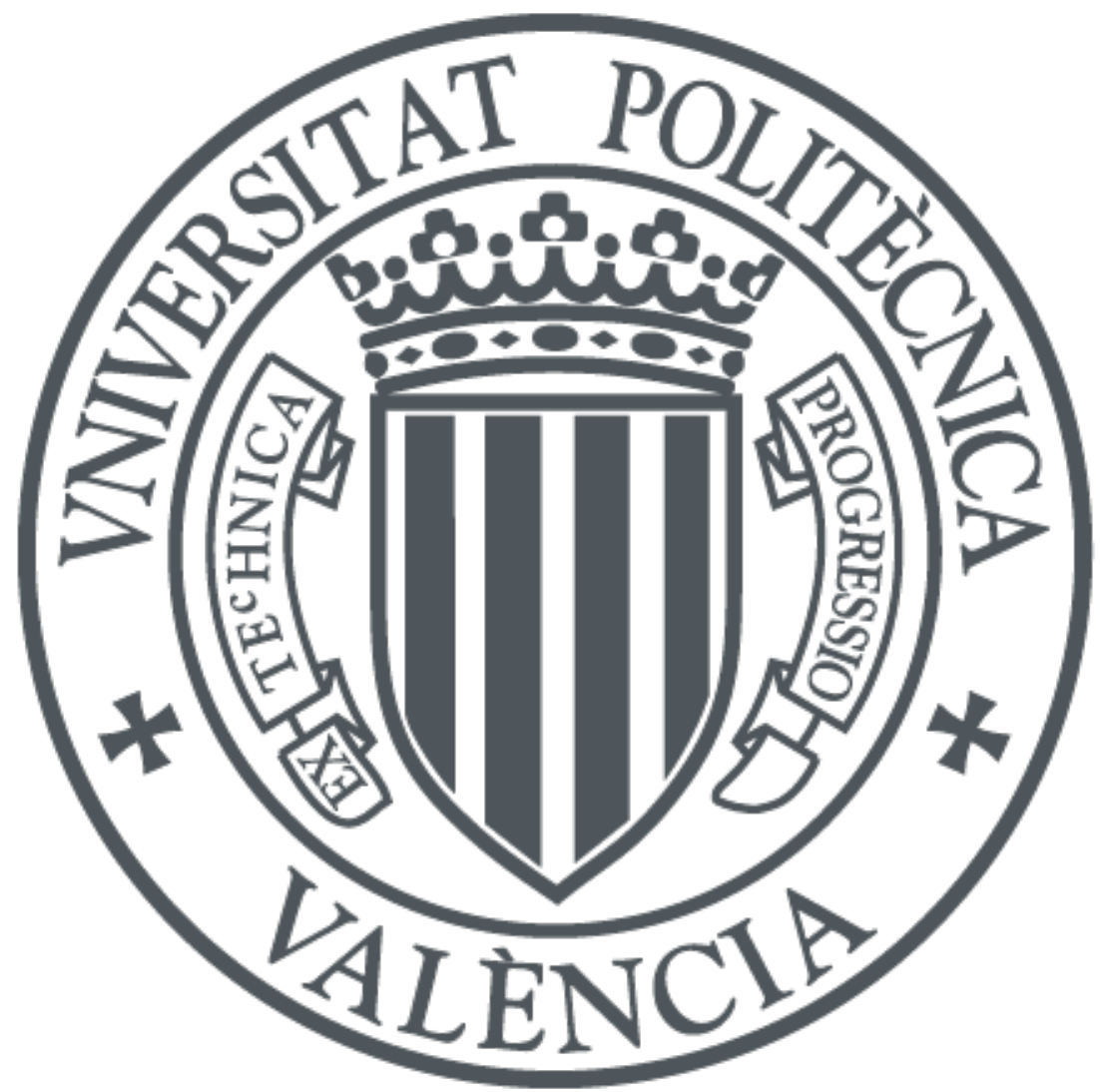

The final publication is available at

https://doi.org/10.1002/cphc.200600337

Copyright John Wiley \& Sons

Additional Information 


\title{
Diastereodifferentiation in Fluorescence Quenching and Excimer Formation in Novel Naphthalene Dyads
}

\author{
Sergio Abad, ${ }^{[a]}$ Ignacio Vayá, ${ }^{[a]}$ M. Consuelo Jiménez, ${ }^{[a] *}$ Uwe Pischel, ${ }^{[a] *}$ Miguel A. \\ Miranda $^{[\mathrm{a}]}$
}

[a] S. Abad, I. Vayá, Dr. C. Jiménez, Dr. U. Pischel, Prof. Dr. M. A. Miranda

Instituto de Tecnología Química UPV-CSIC/ Departamento de Química, Universidad Politécnica de Valencia, Av. de los Naranjos s/n, E-46022 Valencia, Spain

Fax: (+34)-96-387-7809

E-mail: mcjimene@qim.upv.es, upischel@itq.upv.es

\begin{abstract}
Four new bichromophoric naphthalene dyads in form of diastereomeric pairs were synthesized and photophysically characterized. For a closely related group of compounds (1NAP-NAP, 1-MNAP-NAP, 1-MNAP-MNAP) systematic variation of the urea linker led to the observation of intramolecular fluorescence quenching for tertiary urea, but not for secondary urea. Chiral information contained in the dyads had a significant impact on the efficiency of this process. Furthermore, for the case of (R,R)-1-MNAP-MNAP excimer formation in the pre-organized dyad was noted, while being absent in the corresponding $(R, S)$ diastereomer. These differences in photophysical behaviour were ascribed to the geometry of the linker and the chiral information contained in the diastereomeric compounds. Other dyads included naproxen as chromophore. For these compounds excimer emission with a significant diastereodifferentiation was observed for the two investigated stereoisomers.
\end{abstract}

Keywords: diastereomers, excimers, fluorescence, naphthalene, photochemistry 


\section{Introduction}

Formation of excimers as the result of excited-state interactions involving aromatic chromophores is a well-known phenomenon. ${ }^{[1-3]}$ Stabilizing excited state interactions between two $\pi$-systems cause significantly different fluorescence properties of the monomeric chromophore and the excimer, with a red-shifted emission for the latter. Based on these differential photophyscial properties, several fluorescent chemosensors using excimer formation from naphthalene, anthracene or pyrene chromophores have been introduced in recent years. ${ }^{[4]}$ Furthermore, the use of excimer formation for probing the dynamics of polymer chains has been extensively documented. ${ }^{[5]}$

Excimer formation between two chromophores requires close contact within a distance defined by their van-der-Waals radii. Therefore the efficiency of intramolecular excimer formation is dependent on the ease with which both chromophores can approach each other, which is dictated by parameters like temperature, viscosity of the surrounding medium and in the intramolecular case by the conformational freedom of the chromophore-linking spacer. ${ }^{[6,7]}$ One of the most frequently applied rules for intramolecular excimer formation in diaryl systems with polymethylene chains is the so-called Hirayama rule, ${ }^{[8]}$ which predicts the most efficient excimer formation for linkers with three methylene groups. Shorter chains restrict the formation of the typical sandwich-like excimer structures for geometrical reasons, ${ }^{[3]}$ while longer chains provide too much freedom for the two chromophores, akin to intermolecular excimer formation. Besides, chemically more complex linkers like urea functionalities with different degrees of alkylation have been investigated as well. ${ }^{[9,10]}$

However, the influence of chiral information contained in the linker has drawn less attention. There are some examples illustrating the differential photophysical behaviour of diastereomeric dyads with respect to excimer formation between pyrenes including inter- and intramolecular cases. $^{[7,}$ 11] However, naphthalenes have been investigated only occaisonally. ${ }^{[12]}$ Recently, we got interested in the diastereoselective behaviour of dyads 
composed of optically active chromophores of photobiological interest (e.g., 2-arylpropionic acids) and chiral quenchers. We were able to show that stereoselective quenching plays an important role in various mechanistic schemes like electron transfer, hydrogen transfer and

exciplex formation. ${ }^{[13,14]}$ In the present work we have investigated chirality-dependent singlet excimer formation for several bis-naphthalene dyads. We synthesized a diastereomeric couple of naproxen-containing [i.e., 2-(6-methoxynaphth-2-yl)propionic acid] dyads (NPX-NPX) and a series of novel diastereomeric dyads with 1-naphthyl residues linked by secondary and tertiary urea spacers. The structures of the bichromophoric dyads and the respective monomeric model compounds are shown in Chart 1. Steady-state and time-resolved fluorescence measurements allowed us to gain deeper insights into the role of the spacer conformation and chiral information for excimer formation.

-Insert Chart 1 here-

\section{Results}

\section{Measurement of UV/Vis Absorption Spectra}

In Figure 1 the UV/Vis absorption spectra of diastereomeric 1-MNAP-MNAP and NPX-NPX dyads and their respective model compounds (R)-1-NAP-M and (S)-NPX in acetonitrile are shown as examples. The 1-naphthyl derivatives (MNAP-MNAP) showed the typical finestructured UV absorption band with a maximum at $282 \mathrm{~nm}$, while the naproxen-derived dyads displayed their longest wavelength absorption band at $331 \mathrm{~nm}$. These bands were assigned to $\pi, \pi^{*}$ transitions. No significant spectral shifts or changes of the molar absorption coefficients with respect to the model compounds were noted, which supports the absence of strong electronic interactions between both naphthalene chromophores in the ground state.

-Insert Figure 1 here- 


\section{Monomer Fluorescence Quenching of 1-Naphthyl-Containing Dyads with Urea Bridges}

The fluorescence spectra $\left(\lambda_{\mathrm{exc}}=266 \mathrm{~nm}\right)$ of the diastereomeric dyads with urea-linked 1naphthyl residues $[(R, R)$ - and $(R, S)$-combinations] showed a fine-structured band with a maximum at $321 \mathrm{~nm}$ in acetonitrile and $n$-hexane. The same fluorescence emission was found for the monomeric (R)-1-NAP-M model compound. ${ }^{[14]}$ However, the comparison of the fluorescence quantum yields revealed interesting differences, which were also solventdependent ( $c f$. Table 1). In acetonitrile, dyads without methylation of the urea nitrogens (1NAP-NAP) showed no significant fluorescence quenching with respect to the model compound (1-NAP-M) and mono-methylated dyads (1-MNAP-NAP) displayed only weak quenching (ca. $10 \%)$. On the other hand, bis-methylated dyads (1-MNAP-MNAP) showed strong quenching (> $90 \%)$. Also in methanol fluorescence quenching was observed for bismethylated dyads, albeit to a lesser extent (> $50 \%$ ). In $n$-hexane the effects were least pronounced, namely only a weak quenching (ca. $15 \%$ ) for 1-MNAP-MNAP dyads as compared to the model compound 1-NAP-M was noted. The same trend applied to the fluorescence lifetimes ( $c f$. Table 1).

-Insert Figure 2 here-

Strikingly, for the bis-methylated dyads not only the largest quenching effects were observed, but in acetonitrile and methanol also significant differences between the two diastereomers $[(R, R)$ - and $(R, S)-1-\mathrm{MNAP}-\mathrm{MNAP}]$, as shown in Figure 2. Taking the measured quantum yields as basis, for both solvents a two-fold more efficient quenching of the monomer fluorescence for the $(R, S)$ isomer was noted. The fluorescence lifetimes showed the same trend, namely a faster decay for the $(R, S)$ dyad. With the measured lifetimes and eq. 1: $k_{\mathrm{q}}=1 / \tau-1 / \tau_{0}$, the following unimolecular dynamic quenching constants were calculated: $k_{\mathrm{q}}(R, R)=2.8 \times 10^{8} \mathrm{~s}^{-1}$ and $k_{\mathrm{q}}(R, S)=4.4 \times 10^{8} \mathrm{~s}^{-1}$ in acetonitrile; $k_{\mathrm{q}}(R, R)=1.5 \times 10^{7} \mathrm{~s}^{-1}$ and $k_{\mathrm{q}}(R, S)=2.9 \times 10^{7} \mathrm{~s}^{-1}$ in methanol. Calculation of the quenching rate constant by combining steady-state and time-resolved fluorescence data by using eq. 2 : (1- $\left.\Phi_{\mathrm{f}, \mathrm{dyad}} / \Phi_{\mathrm{f}, 1-\mathrm{NAP}-\mathrm{M}}\right) / \tau_{\mathrm{f}, \mathrm{dyad}}$ 
yielded virtually the same values. The thus obtained rate constants express a significant diastereodifferentiation in the intramolecular fluorescence quenching process: $k_{\mathrm{q}}(R, S) / k_{\mathrm{q}}(R, R)$ $=1.6$ and 1.9 in acetonitrile and methanol, respectively. Noteworthy, the quenching rate constant in methanol was one order of magnitude lower than that observed for acetonitrile. This leaded to a slightly higher diastereodifferentiation for the alcohol in accordance with the reactivity-selectivity-principle. On the other hand, in $n$-hexane, the solvent with the smallest quenching effect, no significant difference was noted $\left[k_{\mathrm{q}}(R, R)=3.8 \times 10^{6} \mathrm{~s}^{-1}\right.$ and $k_{\mathrm{q}}(R, S)=$ $\left.3.6 \times 10^{6} \mathrm{~s}^{-1}\right]$

\section{Excimer Formation of 1-Naphthyl-Containing Dyads with Urea Bridges}

As outlined above, the 1-naphthyl-containing dyads with a tertiary urea bridge (1-MNAPMNAP) showed the strongest fluorescence quenching as compared to the other two dyads (1NAP-NAP and 1-MNAP-NAP). In case of the $(R, R)$ diastereomer this quenching process was accompanied by the formation of a broad and red-shifted emission band, which appeared as a shoulder around $400 \mathrm{~nm}$ ( $c f$. Figure 2). Based on the observations made for other bisnaphthalene systems, this new band was assigned to an excimer emission. ${ }^{[2,3]}$ Interestingly, such emission band was not observed for the intermolecular case of 1-methylnaphthalene in acetonitrile solution, even at concentrations up to $10^{-3} \mathrm{M}$. This emphasizes the importance of the linker and the entropy factor for the intramolecular excited state interaction of both chromophores in the dyads. The excitation spectra monitoring the monomer (at $321 \mathrm{~nm}$ ) and excimer emission (at $420 \mathrm{~nm}$ ) were identical ( $c f$. inset in Figure 2a), which excludes excimer formation as the result of ground state dimer excitation.

By contrast with exciplexes, the dipole moment of excimers equals 0 . Therefore, no solvent polarity effects on the excimer emission maximum are expected. This supports our assignment as verified by the invariability of the excimer emission maximum with changing solvent polarity (going from nonpolar $n$-hexane to polar acetonitrile and methanol). 
Strikingly, we observed a remarkable diastereodifferentiation for the excimer formation: only $(R, R)-1$-MNAP-MNAP gave rise to the broad band with a maximum at $c a$. $400 \mathrm{~nm}$, while it was totally absent for the $(R, S)$ diastereomer. Interestingly, the diastereomeric dyad with the smaller monomer fluorescence quenching constant, i.e., $(R, R)-1$ MNAP-MNAP, showed excimer emission. At first glance this seems to be a contradictory observation. However, a possible explanation is that the exclusive excimer formation for the $(R, R)$ combination is paralleled by a major quenching pathway common for both diastereomeric dyads, but more efficient for the $(R, S)$ diastereomer ( $c f$. Discussion).

A closer look at the monomer-to-excimer fluorescence intensity ratios (measured as $\left.I_{321 \mathrm{~nm}} / I_{400 \mathrm{~nm}}\right)$ for $(R, R)-1$-MNAP-MNAP points to the conclusion that excimer formation might not be the dominant monomer quenching pathway. Namely, rather unfavourable ratios of 15:1 (in methanol and $n$-hexane) and 7:1 (in acetonitrile), with preference for the monomer were found.

\section{Fluorescence Quenching and Excimer Formation in Naproxen-Containing Dyads}

The fluorescence spectra $\left(\lambda_{\mathrm{exc}}=266 \mathrm{~nm}\right)$ of the naproxen-containing diastereomeric dyads $[(S, S)$ - and (R,S)-NPX-NPX] and the corresponding model compound (S)-NPX are characterized by an emission band centred at $342 \mathrm{~nm}$ and $350 \mathrm{~nm}$ in $n$-hexane and acetonitrile, respectively. The dyads showed considerable fluorescence quenching (ca. $70 \%$ in acetonitrile and ca. $90 \%$ in $n$-hexane) with respect to the model compound (cf. Figure 3). The quenching was accompanied by formation of a broad and red-shifted emission band with a maximum at $c a .395 \mathrm{~nm}$, which was assigned to excimer-related fluorescence. ${ }^{[15]}$ As noted for 1-methylnaphthalene, also 2-methoxynaphthalene showed no intermolecular excimer formation in acetonitrile (up to $10^{-3} \mathrm{M}$ ). Like discussed also above, no significant shift of the broad emission band was observed upon going from nonpolar $n$-hexane to polar acetonitrile, which is in agreement with our assignment. The excitation spectra monitoring the monomer and excimer emission showed no differences, excluding excimer formation by excitation of 
ground state dimers. Contrary to the observations made for the above discussed naphthalene dyads, excimer formation seems to be the major quenching pathway in the NPX-NPX dyads, as reflected by the considerably larger ratio of monomer-to-excimer fluorescence, i.e., $I_{342}$ $\mathrm{nm} / I_{395} \mathrm{~nm}=0.8$ in $n$-hexane and $I_{350 \mathrm{~nm}} / I_{395} \mathrm{~nm}=1.7-2.0$ in acetonitrile. According to eq. 1 unimolecular dynamic quenching rate constants of $6.3 \times 10^{8} \mathrm{~s}^{-1}$ and $6.5 \times 10^{8} \mathrm{~s}^{-1}$ in acetonitrile and $n$-hexane, respectively, were calculated (see lifetimes in Table 1). However, no diastereodifferentiation at the level of monomer fluorescence quenching was noted. The intensity of excimer fluorescence showed small differences in acetonitrile, with the stronger excimer fluorescence for $(R, S)-\mathrm{NPX}-\mathrm{NPX}$ (factor $c a$. 1.2, $c f$. Figure 3). The same trend is expressed by the measured lifetimes $\left(\lambda_{\mathrm{obs}}=430 \mathrm{~nm}\right)$ of excimer fluorescence, which indicates that the $(R, S)$ excimer deactivates slower than the $(S, S)$ excimer, i.e., $\tau_{\mathrm{f}}=23.9$ ns versus 28.0 ns in acetonitrile ( $c f$. Figure 4). However, in $n$-hexane a smaller differentiation of the excimer deactivation was observed [29.0 versus 31.0 ns for $(S, S)$ and $(R, S)$, respectively]. This points to a differential non-radiative deactivation rate constant for both diastereomers.

-Insert Figures 3 and 4 here-

\section{Discussion}

\section{Quenching Pathways in Urea-Linked Dyads}

For the diastereomeric dyads with a tertiary urea linker we observed strong quenching of fluorescence monomer which is dependent on the solvent. For $(R, R)-1-\mathrm{MNAP}-\mathrm{MNAP}$ the quenching is accompanied by concomitant formation of excimer, as identified by the characteristic fluorescence emission. Clearly, this pathway is one contributor to the monomer fluorescence quenching. However, the quite unfavourable monomer-to-excimer fluorescence intensity ratio and moreover the total absence of excimer fluorescence for $(R, S)$-1-MNAPMNAP, albeit showing the strongest monomer fluorescence quenching, suggests the 
occurrence of an additional parallel quenching pathway. Singlet-singlet energy transfer can be excluded, since both chromophores are identical. Photoinduced electron transfer between an excited state and a ground state chromophore also does not offer a satisfying explanation, since this process would be thermoneutral $\left(\Delta G_{\mathrm{et}}=+0.04 \mathrm{eV}\right.$ in acetonitrile $){ }^{[16]}$ in agreement with the absence of any radical ion transient in time-resolved laser-flash-photolysis experiments. Instead of, only a signal at $430 \mathrm{~nm}$, which was assigned as triplet-triplet absorption of naphthalene, was observed. On the other hand, self-quenching is a likely and alternative non-radiative deactivation pathway. ${ }^{[17]}$ Similar observations of monomer fluorescence quenching without excimer formation, which have been attributed to selfquenching, were for dendrimers with peripheral anthracene units. ${ }^{[18]}$ Also the possibility of a photoreaction as deactivation channel of singlet-excited naphthalenes should be considered. Indeed, a control experiment showed that the irradiation of 1-MNAP-MNAP dyads at $\lambda_{\text {exc }}=$ $254 \mathrm{~nm}$ leads to permanent changes in the absorption spectrum accompanied. This was confirmed by HPLC measurements, which clearly showed the decomposition of the dyads. ${ }^{[19]}$

\section{Dependence of the Photophysical Behaviour on the Urea Linker Conformation}

As outlined above, significant quenching of the monomer naphthalene fluorescence was only observed for the bis-methylated dyads (1-MNAP-MNAP). This might be rationalized by having a closer look at the linker conformation in dependence on the degree of urea $\mathrm{N}$ methylation. As described by Lewis et al. $N, N^{\prime}$-diarylurea with tertiary urea linkers give rise to a folded conformation, while secondary urea bridges lead to extended conformations. ${ }^{[9]}$ This structural difference can be traced back to steric hindrance between two urea $N$ alkyl substituents, which is reduced for the trans,trans arrangement, bringing the two aryl residues in close proximity. This ground state pre-organization favours excited state excimer formation as well as intramolecular self-quenching. However, in our systems the aryl residues are not directly connected to the urea nitrogen, therefore this type of pre-organization is expected to be less dominant than in $N, N^{\prime}$-diarylureas. Some insight into solution ground state interactions 
between the two naphthyl chromophores can be obtained from the analysis of the ${ }^{1} \mathrm{H}$ NMR spectra. In case of interactions between both aromatic residues upfield shifts of the aromatic proton signals would be expected and actually these were observed for similar cases. For dyads with secondary urea (1-NAP-NAP and 1-MNAP-NAP) we did not see such shifts. However, in the case of $(R, R)$-MNAP-MNAP the aromatic protons were clearly upfield shifted (ca. 0.2-0.4 ppm, depending on the solvent, i.e., chloroform, acetone, acetonitrile, methanol) as compared to $(R, S)-1-M N A P-M N A P$ and also $(R)-1-N A P-M$. This is shown in Figure 5 for acetonitrile. Noteworthy, this observation coincided with the exclusive excimer formation for $(R, R)-1$-MNAP-MNAP. Obviously, the ground state pre-organization of the chromophores facilitates their parallel alignment in the excited state resulting in the observed excimers. Here it must be mentioned that ground state pre-organization is not equivalent with dimer formation via electronic $\pi-\pi$ interactions. The observed upfield shift of aromatic protons clearly supports that both chromophores are tilted with respect to each other. Furthermore, neither differences in the absorption spectra of $(R, R)-1$-MNAP-MNAP and the (R)-1-NAP-M model compound nor variations in the excitation spectra monitoring monomer and excimer emission were noted, which is in disagreement with dimer excitation.

-Insert Figure 5 here-

In a further attempt to gain more insights into the role of the linker geometry we performed semiempirical AM1 calculations with model compounds: ${ }^{[20]} N, N^{\prime}$-diisopropylureas with varying degrees of methylation $\left(n_{\mathrm{CH}_{3}}=0,1,2\right)$. Calculations with the synthesized dyads were omitted for the reason of the high number of possible rotamers, which would complicate the search for the global minimum on the potential hypersurface. In agreement with the reported gas phase structure of parent urea, nonplanar anti geometries were obtained as minimum energy structures (i.e., cis,cis and trans, trans). ${ }^{[9]}$ The calculated heats of formation $\left(\Delta H_{\mathrm{f}}\right)$ of the linker models support a clear trend ( $c f$. Table 2): independent on the degree of methylation, the cis,cis conformation is preferred. However, in case of the bis-methylated 
linker the cis,cis to trans,trans conversion has the smallest activation barrier as compared to partially or non-methylated linkers (rated by the energy difference between both conformers: $\Delta E_{\text {cis,cis } \rightarrow \text { trans,trans }}$ ca. $0.1 \mathrm{kcal} \mathrm{mol}{ }^{-1}$ for $n_{\mathrm{CH}_{3}}=2$ versus $1.5-2.5 \mathrm{kcal} \mathrm{mol}^{-1}$ for $\left.n_{\mathrm{CH}_{3}}=0,1\right)$. The cis,cis geometry of the linker would lead to an extended conformation of the dyads, while trans,trans facilitates the spatial approach of both chromophores and consequently excimer formation and/or self-quenching. As can be deduced from the nearly barrierless conversion between both linker geometries in case of 1-MNAP-MNAP, an approach of both naphthyl residues is more likely than for the other dyads with secondary urea nitrogens.

-Insert Figure 6 here-

\section{Photophysical Behaviour of Naproxen-Containing Dyads}

For the NPX-NPX dyads the mechanistic picture seems to be simpler. Excimer fluorescence in the emission spectra of the dyads in acetonitrile and $n$-hexane is dominant, which suggests that formation of this species is the main quenching pathway of monomer fluorescence. A closer inspection of the ${ }^{1} \mathrm{H}$ NMR spectra of both NPX-NPX dyads and (S)-NPX as model compound revealed similar upfield shifts (ca. $0.2 \mathrm{ppm})$ of aromatic proton signals as observed for $(R, R)$-MNAP-MNAP ( $c f$. Figure 6). However, in this case both diastereomeric dyads showed such shifts in agreement with the observed strong excimer fluorescence. Akin to the argumentation used above, ground state pre-organization of the naproxen chromophores facilitates excimer formation.

\section{Diastereoselectivity in the Quenching Processes}

-Insert Scheme 1 here-

One motivation of the present study was the clarification of the role of diastereoselectivity in the quenching processes, which occur in the novel dyads. Indeed, we observed a marked dependence of the photophysical behaviour on the chiral information at different levels (i.e., monomer fluorescence quenching, excimer formation and deactivation). The monomer fluorescence quenching in the 1-MNAP-MNAP dyads was significantly dependent on the 
chiral information. We assume that this process is related to a combination of (a) nonradiative self-quenching and (b) excimer formation ( $c f$. Scheme 1). The observation of excimer fluorescence showed a unique diastereoselectivity, favouring the $(R, R)-1$-MNAPMNAP dyad, which finds experimental support in the exclusive observation of ground state interactions for this isomer. Hence, the pre-organization of both chromophores is a precondition for excimer formation. On the other hand, the approach of the naphthyl residues during the excited state lifetime leads to non-radiative self-quenching (including photodecomposition) without the formation of excimers. This is in agreement with the strong monomer quenching of the $(R, S)$-1-MNAP-MNAP dyad, which does not show signs for ground state pre-organization. As supported by the semiempirical AM1 calculations for model urea linkers (see above), the approach of both naphthyl rings is least hindered for tertiary urea.

Naproxen-containing dyads (NPX-NPX), on the other hand, gave rise to the observation of strong excimer formation, albeit significant diastereodifferentiation was only observed for excimer deactivation via non-radiative pathways (i.e., return to the ground state, triplet state population).

\section{Conclusions}

The photophysical properties of diastereomeric bis-naphthalene dyads with respect to their potential to form excimers was investigated. Two types of compounds were synthesized, namely dyads with 1-naphthyl residues linked by urea spacers and naproxen-containing dyads with an ester bridge. For the dyads with urea linkers marked differences in the monomer fluorescence quenching (via self-quenching and excimer formation) depending on the linker geometry were noted. Furthermore, the formation of excimers was restricted to $(R, R)-1$ MNAP-MNAP, supported by ground state pre-organization as evidenced by ${ }^{1} \mathrm{H}$ NMR. On the other hand, naproxen-containing dyads showed preferential excited singlet state quenching via excimer formation. Again, this is in agreement with the observed ground state pre- 
organization. However, diastereomeric NPX-NPX dyads lack significant differences in their photophysical behaviour.

The obtained results show that observation of intramolecular excimers is a delicate balance between the electronic nature of the chromophore (1-naphthyl versus naproxen), the linker geometry, chirality and ground state pre-organization.

\section{Experimental Section}

Materials: All chemicals for the synthesis of the dyads and the model compound as well as (S)-naproxen were purchased from Aldrich. (R)-2-(6-Methoxynaphth-2-yl)propionic acid [(R)-naproxen] was from Chiro Technology. $n$-Hexane, acetonitrile and methanol, which were used for photophysical measurements, were of HPLC quality from Merck. Silica gel (230-400 mesh) from Scharlau was used for column chromatography. Ethyl acetate, $n$-hexane and dichloromethane from Scharlau were used for flash chromatography as well as for recrystallization. The solvents for NMR ( $d$-chloroform, $d_{3}$-acetonitrile, $d_{6}$-acetone, $d_{4}$ methanol, $d_{6}$-dimethylsulfoxide, all $>99.5$ atom \% D) were from Panreac.

Spectroscopic Measurements: Spectroscopic measurements were performed at room temperature with nitrogen-purged solutions in acetonitrile and $n$-hexane. Additionally, the fluorescence properties of 1-MNAP-MNAP dyads were also examined in methanol. Cuvettes were of $1 \mathrm{~cm}$ optical path length and for fluorescence measurements the absorbance at the excitation wavelength $(266 \mathrm{~nm})$ was kept at $c a .0 .2$ in order to avoid non-linear effects. UV/Vis-absorption measurements were performed with a Shimadzu UV-2101 spectrometer. Steady-state fluorescence spectra were recorded on a Photon Technology International (PTI) LPS-220B fluorimeter or on a FS900 from Edinburgh Instruments. Time-resolved measurements were made with a lifetime spectrometer (TimeMaster fluorescence lifetime spectrometer TM-2/2003) from PTI by means of the stroboscopic technique, which is a variation of the boxcar technique. As excitation source a hydrogen/nitrogen flashlamp (1.8 ns 
pulse width) was used. In some cases, lifetimes measurements were done with a singlephoton-technique using a FL900 setup from Edinburgh Instrument equipped with a hydrogen flashlamp (1.5 ns pulse width) as excitation wavelength. No significant differences between the results obtained on either equipment were found. The kinetic traces were fitted by monoor biexponential decay functions using a re-convolution procedure to separate from the lamp pulse profile.

Preparation of 1-NAP-NAP Diastereomers: The synthesis was performed by reaction of [(R)-1-(naphth-1-yl)ethyl]isocyanate $(1.0 \mathrm{mmol})$ with $(R)$ - or $(S)$-1-naphthylethylamine $(1.2$ mmol) in dry dichloromethane $(10 \mathrm{~mL})$. The mxiture was stirred at room temperature for 3 hours. The precipitated products were purified by recrystallization from the same solvent and obtained as colorless solids.

$N, N^{\prime}$-Bis[1-(R)-(naphth-1-yl)ethyl]urea $\quad[(R, R)-1-N A P-N A P]:{ }^{1} \mathrm{H} \quad \mathrm{NMR} \quad\left(300 \mathrm{MHz}, d_{6^{-}}\right.$ DMSO): $\delta=8.07-8.18(\mathrm{~m}, 2 \mathrm{H}), 7.87-7.97(\mathrm{~m}, 2 \mathrm{H}), 7.76-7.86(\mathrm{~m}, 2 \mathrm{H}), 7.41-7.61(\mathrm{~m}, 8 \mathrm{H})$, $6.44(\mathrm{~m}, 2 \mathrm{H}), 5.45-5.60(\mathrm{~m}, 2 \mathrm{H}), 1.43\left(\mathrm{~d},{ }^{3} \mathrm{~J}(\mathrm{H}, \mathrm{H})=6.8 \mathrm{~Hz}, 6 \mathrm{H}\right) .{ }^{13} \mathrm{C}$ NMR $\left(75 \mathrm{MHz}, d_{6^{-}}\right.$ DMSO): $\delta=156.8,141.6,133.8,130.7,129.0,127.4,126.4,125.9,125.8,123.6,122.3,45.0$, 22.7. HRMS (EI) calcd for $\mathrm{C}_{25} \mathrm{H}_{24} \mathrm{~N}_{2} \mathrm{O}$ : 368.1889; found: 368.1891.

$N$-[1-(R)-(Naphth-1-yl)ethyl]- $N^{\prime}$-[1-(S)-(naphth-1-yl)ethyl]urea $\quad[(R, S)-1-N A P-N A P]: \quad{ }^{1} \mathrm{H}$ NMR (300 MHz, $d_{6}$-DMSO): $\delta=8.03-8.10$ (m, 2H), 7.88-7.95 (m, 2H), 7.76-7.83 (m, 2H), 7.42-7.54 (m, 8H), 6.39 (m, 2H), 5.47-5.58 (m, 2H), $1.48\left(\mathrm{~d},{ }^{3} \mathrm{~J}(\mathrm{H}, \mathrm{H})=6.8 \mathrm{~Hz}, 6 \mathrm{H}\right) .{ }^{13} \mathrm{C}$ NMR (75 MHz, $d_{6}$-DMSO): $\delta=156.7,141.4,133.8,130.7,128.9,127.5,126.4,125.9,125.7$, 123.6, 122.2, 45.0, 22.6. HRMS (EI) calcd for $\mathrm{C}_{25} \mathrm{H}_{24} \mathrm{~N}_{2} \mathrm{O}$ : 368.1889; found: 368.1854.

Preparation of 1-MNAP-NAP and 1-MNAP-MNAP Diastereomers: Sodium hydride (2.0 mmol) in $N, N$-dimethylformamide $(1 \mathrm{~mL})$ was added slowly to a solution of $(R, R)$ - or $(R, S)$-1NAP-NAP $(1.0 \mathrm{mmol})$ in the same solvent $(2 \mathrm{~mL})$, followed by the addition of methyl iodide (2.0 mmol). The mixture was stirred at room temperature for 2 hours. After standard aqueous work-up the obtained mixture of mono- and bis-methylated ureas was resolved by flash 
chromatography over silica gel using acetone/n-hexane (v/v 1/4) as eluent. The products were obtained as colorless solids. The $(R, S)$-mono-methylated dyad was obtained as racemic mixture of the two possible enantiomers and not further resolved.

$N, N^{\prime}$-Bis[1-(R)-(naphth-1-yl)ethyl]- $N$-methylurea $\quad[(R, R)-1-\mathrm{MNAP}-\mathrm{NAP}]:{ }^{1} \mathrm{H} \quad \mathrm{NMR} \quad$ (300 $\left.\mathrm{MHz}, \mathrm{CDCl}_{3}\right): \delta=8.27(\mathrm{~m}, 2 \mathrm{H}), 7.75-7.91(\mathrm{~m}, 4 \mathrm{H}), 7.39-7.64(\mathrm{~m}, 8 \mathrm{H}), 6.38\left(\mathrm{q},{ }^{3} \mathrm{~J}(\mathrm{H}, \mathrm{H})=\right.$ $7.0 \mathrm{~Hz}, 1 \mathrm{H}), 5.93-6.05\left(\mathrm{~m},{ }^{3} J_{1}(\mathrm{H}, \mathrm{H})=7.9 \mathrm{~Hz},{ }^{3} J_{2}(\mathrm{H}, \mathrm{H})=6.8 \mathrm{~Hz}, 1 \mathrm{H}\right), 4.59\left(\mathrm{~d},{ }^{3} J(\mathrm{H}, \mathrm{H})=\right.$ $7.9 \mathrm{~Hz}, 1 \mathrm{H}), 2.35$ (s, 3H), $1.68\left(\mathrm{~d},{ }^{3} J(\mathrm{H}, \mathrm{H})=6.8 \mathrm{~Hz}, 3 \mathrm{H}\right), 1.60\left(\mathrm{~d},{ }^{3} J(\mathrm{H}, \mathrm{H})=7.0 \mathrm{~Hz}, 3 \mathrm{H}\right)$. ${ }^{13} \mathrm{C}$ NMR (75 MHz, $\left.\mathrm{CDCl}_{3}\right): \delta=157.2,140.0,137.3,134.4,134.3,132.5,131.7,129.1$, 128.9, 128.9, 128.4, 127.0, 126.8, 126.2, 126.1, 125.6, 125.2, 124.8, 124.7, 124.2, 122.7, 49.5, 46.4, 28.4, 22.2, 16.8. HRMS (EI) calcd for $\mathrm{C}_{26} \mathrm{H}_{26} \mathrm{~N}_{2} \mathrm{O}$ : 382.2045; found: 382.2031.

$N$-Methyl- $N$-[1-(R)-(naphth-1-yl)ethyl]- $N^{\prime}$-[1-(S)-(naphth-1-yl)ethyl]urea and $N$-Methyl- $N$-[1(S)-(naphth-1-yl)ethyl]- $N^{\prime}$-[1-(R)-(naphth-1-yl)ethyl]urea $\quad[(R, S) /(S, R)-1-\mathrm{MNAP}-\mathrm{NAP}]: \quad{ }^{1} \mathrm{H}$ NMR $\left(300 \mathrm{MHz}, \mathrm{CDCl}_{3}\right): \delta=8.25\left(\mathrm{~d},{ }^{3} J_{1}(\mathrm{H}, \mathrm{H})=8.1 \mathrm{~Hz}, 1 \mathrm{H}\right), 8.14\left(\mathrm{~d},{ }^{3} J_{1}(\mathrm{H}, \mathrm{H})=8.1 \mathrm{~Hz}\right.$, 1H), 7.72-7.89 (m, 4H), 7.35-7.55 (m, 8H), $6.38\left(\mathrm{q},{ }^{3} J(\mathrm{H}, \mathrm{H})=6.8 \mathrm{~Hz}, 1 \mathrm{H}\right), 5.88-6.01\left(\mathrm{~m},{ }^{3} J_{1}\right.$ $\left.(\mathrm{H}, \mathrm{H})=7.0 \mathrm{~Hz},{ }^{3} J_{2}(\mathrm{H}, \mathrm{H})=6.8 \mathrm{~Hz}, 1 \mathrm{H}\right), 4.61\left(\mathrm{~d},{ }^{3} \mathrm{~J}(\mathrm{H}, \mathrm{H})=7.0 \mathrm{~Hz}, 1 \mathrm{H}\right), 2.35(\mathrm{~s}, 3 \mathrm{H}), 1.70$ $\left(\mathrm{d},{ }^{3} J(\mathrm{H}, \mathrm{H})=6.8 \mathrm{~Hz}, 3 \mathrm{H}\right), 1.64\left(\mathrm{~d},{ }^{3} J(\mathrm{H}, \mathrm{H})=6.8 \mathrm{~Hz}, 3 \mathrm{H}\right) .{ }^{13} \mathrm{C}$ NMR $\left(75 \mathrm{MHz}, \mathrm{CDCl}_{3}\right): \delta=$ 157.0, 140.2, 137.3, 134.4, 134.1, 132.4, 131.5, 129.0, 128.8, 128.3, 127.0, 126.7, 126.1, 126.0, 125.5, 125.1, 124.7, 124.7, 124.0, 122.3, 49.4, 46.6, 28.4, 22.1, 16.7. HRMS (EI) calcd for $\mathrm{C}_{26} \mathrm{H}_{26} \mathrm{~N}_{2} \mathrm{O}$ : 382.2045; found: 382.2025 .

$N, N^{\prime}$-Bis[1-(R)-(naphth-1-yl)ethyl]- $N, N^{\prime}$-dimethylurea $\quad[(R, R)-1-M N A P-M N A P]: \quad{ }^{1} \mathrm{H} \quad \mathrm{NMR}$ (300 MHz, $\left.\mathrm{CDCl}_{3}\right): \delta=7.73-7.97(\mathrm{~m}, 6 \mathrm{H}), 7.39-7.55(\mathrm{~m}, 8 \mathrm{H}), 6.00\left(\mathrm{q},{ }^{3} \mathrm{~J}(\mathrm{H}, \mathrm{H})=6.8 \mathrm{~Hz}\right.$, 2H), $2.13(\mathrm{~s}, 6 \mathrm{H}), 1.83\left(\mathrm{~d},{ }^{3} \mathrm{~J}(\mathrm{H}, \mathrm{H})=6.8 \mathrm{~Hz}, 6 \mathrm{H}\right) .{ }^{13} \mathrm{C} \mathrm{NMR}\left(75 \mathrm{MHz}, \mathrm{CDCl}_{3}\right): \delta=164.3$, 137.5, 134.3, 132.3, 129.1, 128.6, 126.5, 126.1, 125.3, 124.6, 124.1, 51.3, 31.3, 15.3. HRMS (EI) calcd for $\mathrm{C}_{27} \mathrm{H}_{28} \mathrm{~N}_{2} \mathrm{O}$ : 396.2202. Found: 396.2195.

$N, N^{\prime}$-Dimethyl- $N$-[1-(R)-(naphth-1-yl)ethyl]- $N^{\prime}$-[1-(S)-(naphth-1-yl)ethyl]urea $\quad[(R, S)-1$ MNAP-MNAP]: ${ }^{1} \mathrm{H}$ NMR (300 MHz, $\left.\mathrm{CDCl}_{3}\right): \delta=8.10\left(\mathrm{~d},{ }^{3} J(\mathrm{H}, \mathrm{H})=8.3 \mathrm{~Hz}, 2 \mathrm{H}\right), 7.86\left(\mathrm{~d},{ }^{3} \mathrm{~J}\right.$ 
$(\mathrm{H}, \mathrm{H})=7.9 \mathrm{~Hz}, 2 \mathrm{H}), 7.76\left(\mathrm{~d},{ }^{3} J(\mathrm{H}, \mathrm{H})=8.1,2 \mathrm{H}\right), 7.33-7.55(\mathrm{~m}, 8 \mathrm{H}), 5.97\left(\mathrm{q},{ }^{3} J(\mathrm{H}, \mathrm{H})=\right.$ 6.8Hz, 2H), $2.33(\mathrm{~s}, 6 \mathrm{H}), 1.70\left(\mathrm{~d},{ }^{3} J(\mathrm{H}, \mathrm{H})=6.8 \mathrm{~Hz}, 6 \mathrm{H}\right) .{ }^{13} \mathrm{C} \mathrm{NMR}\left(75 \mathrm{MHz}, \mathrm{CDCl}_{3}\right): \delta=$ 164.6, 138.0, 134.3, 132.1, 129.0, 128.5, 126.6, 126.0, 125.4, 124.6, 124.4, 52.3, 32.0, 17.1. HRMS (EI) calcd for $\mathrm{C}_{27} \mathrm{H}_{28} \mathrm{~N}_{2} \mathrm{O}$ : 396.2202; found: 396.2194.

Preparation of NPX-NPX Diastereomers: The synthesis was accomplished by dropwise addition of $(S)$-naproxen $(2.0 \mathrm{mmol})$ in diethylether $(15 \mathrm{~mL})$ to a solution of $\mathrm{LiAlH}_{4}(8.0$ mmol) in the same solvent $(10 \mathrm{~mL})$. The mixture was refluxed for 3 hours. After standard aqueous work-up the crude alcohol was obtained and purified by flash chromatography (ethyl acetate/dichloromethane, v/v 10/1). Subsequently, the alcohol (0.8 mmol) was reacted with $(S)$ - or $(R)$-naproxen $(1.0 \mathrm{mmol})$ in dry dichloromethane $(10 \mathrm{~mL})$, using 1-(3dimethylaminopropyl)- $N$-ethylcarbodiimide hydrochloride $(1.0 \mathrm{mmol})$ for activation of the acid. After standard work-up the products were purified by flash chromatography (nhexane/dichloromethane, v/v 1/4) and subsequently recrystallized from ethyl acetate/nhexane.

[2-(S)-(6-Methoxynaphth-2-yl)]propyl [2-(S)-(6-methoxynaphth-2-yl)]propanoate $\quad[(S, S)-$ NPX-NPX]: ${ }^{1} \mathrm{H}$ NMR (300 MHz, $\left.\mathrm{CDCl}_{3}\right): \delta$ = 7.01-7.62 (m, 12H), 4.24 (m, 2H), 3.91 (s, 3H), 3.90 (s, 3H), 3.77 (q, $\left.{ }^{3} J(\mathrm{H}, \mathrm{H})=7.2 \mathrm{~Hz}, 1 \mathrm{H}\right), 3.14(\mathrm{~m}, 1 \mathrm{H}), 1.50\left(\mathrm{~d},{ }^{3} J(\mathrm{H}, \mathrm{H})=7.2 \mathrm{~Hz}, 3 \mathrm{H}\right)$, $1.26\left(\mathrm{~d},{ }^{3} \mathrm{~J}(\mathrm{H}, \mathrm{H})=7.2 \mathrm{~Hz}, 3 \mathrm{H}\right) .{ }^{13} \mathrm{C} \mathrm{NMR}\left(75 \mathrm{MHz}^{\mathrm{CDCl}} \mathrm{)}\right): \delta=174.8,157.9,157.6,138.5$, 135.9, 133.9, 133.7, 129.6, 129.5, 129.4, 129.2, 127.3, 127.1, 126.5, 126.4, 126.2, 125.8, 119.1, 119.0, 105.8, 69.9, 55.6, 45.8, 39.1, 18.6, 18.3. Elemental analysis calcd for $\mathrm{C}_{28} \mathrm{H}_{28} \mathrm{O}_{4}$ : C 78.48, H 6.59; found: C 77.96, H 6.57.

[2-(R)-(6-Methoxynaphth-2-yl)]propyl [2-(S)-(6-methoxynaphth-2-yl)]propanoate $\quad[(R, S)-$ NPX-NPX]: ${ }^{1} \mathrm{H}$ NMR (300 MHz, $\left.\mathrm{CDCl}_{3}\right): \delta=7.00-7.60(\mathrm{~m}, 12 \mathrm{H}), 4.33\left(\mathrm{dd},{ }^{2} J(\mathrm{H}, \mathrm{H})=11.0\right.$ $\left.\mathrm{Hz},{ }^{3} J(\mathrm{H}, \mathrm{H})=7.1 \mathrm{~Hz}, 1 \mathrm{H}\right), 4.16\left(\mathrm{dd},{ }^{2} J(\mathrm{H}, \mathrm{H})=11.0 \mathrm{~Hz},{ }^{3} J(\mathrm{H}, \mathrm{H})=6.6 \mathrm{~Hz}, 1 \mathrm{H}\right), 3.92(\mathrm{~s}$, 3H), $3.90(\mathrm{~s}, 3 \mathrm{H}), 3.77\left(\mathrm{q},{ }^{3} J(\mathrm{H}, \mathrm{H})=7.1 \mathrm{~Hz}, 1 \mathrm{H}\right), 3.14(\mathrm{~m}, 1 \mathrm{H}), 1.50\left(\mathrm{~d},{ }^{3} J(\mathrm{H}, \mathrm{H})=7.1 \mathrm{~Hz}\right.$, 3H), $1.26\left(\mathrm{~d},{ }^{3} \mathrm{~J}(\mathrm{H}, \mathrm{H})=7.1 \mathrm{~Hz}, 3 \mathrm{H}\right) .{ }^{13} \mathrm{C} \mathrm{NMR}\left(75 \mathrm{MHz}, \mathrm{CDCl}_{3}\right): \delta=174.8,157.8,138.4$, 
135.8, 133.7, 129.5, 129.4, 129.2, 129.1, 127.3, 127.1, 126.5, 126.4, 126.2, 125.8, 119.1, 119.0, 105.8, 69.8, 55.6, 45.8, 39.1, 18.5, 18.3. Elemental analysis calcd for $\mathrm{C}_{28} \mathrm{H}_{28} \mathrm{O}_{4}$ : C 78.48, H 6.57; found: C 78.67, H 6.62.

X-ray: CCDC $\operatorname{xxxx}[(S, S)-N P X-N P X]$ and CCDC $\operatorname{xxxx}[(R, S)-N P X-N P X]$ contain the supplementary crystallographic data for this paper. These data can be obtained free of charge via www.ccdc.cam.ac.uk/data_request/cif, or by emailing data_request@ccdc.cam.ac.uk, or by contacting The Cambridge Crystallographic Data Centre, 12, Union Road, Cambridge CB2 1EZ, UK; fax: (+44)-1223-336033.

\section{Acknowledgements}

We acknowledge the financial support by the Spanish Ministry of Education and Science [Grant No. CTQ 2004-03811, doctoral fellowships for (S.A., I.V.) and Ramon y Cajal grant for U.P.].

\section{References}

[1] a) T. Förster, K. Kasper, Z. Electrochem. 1955, 59, 976-980; b) I. B. Berlman, J. Chem. Phys. 1961, 34, 1083-1084; c) I. B. Berlman, Nature 1961, 161, 594-595; d) J. B. Birks, L. G. Christophorou, Nature 1962, 194, 442-444; e) J. B. Birks, L. G. Christophorou, Nature 1962, 196, 33-35; f) J. B. Birks, L. G. Christophorou, Nature 1963, 197, 1064-1065; g) E. A. Chandross, J. Ferguson, J. Chem. Phys. 1966, 45, 397-398.

[2] a) J. B. Birks, Photophysics of Aromatic Molecules, Wiley, New York, 1970; b) E. A. Chandross, C. J. Dempster, J. Am. Chem. Soc. 1970, 92, 704-706.

[3] E. A. Chandross, C. J. Dempster, J. Am. Chem. Soc. 1970, 92, 3586-3593. 
[4] a) Y. Shiraishi, Y. Tokitoh, G. Nishimura, T. Hirai, Org. Lett. 2005, 7, 2611-2614; b) J. Pina, J. S. de Melo, F. Pina, C. Lodeiro, J. C. Lima, A. J. Parola, C. Soriano, M. P. Clares, M. T. Albelda, R. Aucejo, E. García-España, Inorg. Chem. 2005, 44, 74497458; c) S. H. Lee, S. H. Kim, S. K. Kim, J. H. Jung, J. S. Kim, J. Org. Chem. 2005, 70, 9288-9295; d) S. K. Kim, J. H. Bok, R. A. Bartsch, J. Y. Lee, J. S. Kim, Org. Lett. 2005, 7, 4839-4842; e) K. H. Cho, D. H. Lee, J.-I. Hong, Chem. Commun. 2005, 1690-1692; f) A. Okamoto, T. Ichiba, I. Saito, J. Am. Chem. Soc. 2004, 126, 83648365; g) S. K. Kim, S. H. Lee, J. Y. Lee, J. Y. Lee, R. A. Bartsch, J. S. Kim, J. Am. Chem. Soc. 2004, 126, 16499-16506; h) I. Leray, J. Lefevre, J. Delouis, J. Delaire, B. Valeur, Chem. Eur. J. 2001, 7, 4590-4598; i) R. Krauss, H.-G. Weinig, M. Seydack, J. Bendig, U. Koert, Angew. Chem. Int. Ed. 2000, 39, 1835-1837; j) S. Nishizawa, Y. Kato, N. Teramae, J. Am. Chem. Soc. 1999, 121, 9463-9464.

[5] a) H. Itagaki, N. Obukata, A. Okamoto, K. Horie, I. Mita, J. Am. Chem. Soc. 1982, 104, 4469-4477; b) D. Phillips, Polymer Photophysics, Chapman and Hall, New York, 1985; c) M. A. Winnik, Acc. Chem. Res. 1985, 18, 73-79; d) F. Mendicuti, R. Kulkarni, B. Patel, W. L. Mattice, Macromolecules 1990, 23, 2560-2566; e) Y. Gan, D. Dong, S. Carlotti, T. E. Hogen-Esch, J. Am. Chem. Soc. 2000, 122, 2130-2131.

[6] a) N. J. Turro, M. Aikawa, A. Yekta, J. Am. Chem. Soc. 1979, 101, 772-774; b) R. Todesco, J. Gelan, H. Martens, J. Put, F. C. De Schryver, J. Am. Chem. Soc. 1981, 103, 7304-7312.

[7] F. C. De Schryver, P. Collart, J. Vandendriessche, R. Goedeweeck, A. M. Swinnen, M. Van Der Auweraer, Acc. Chem. Res. 1987, 20, 159-166.

[8] F. Hirayama, J. Chem. Phys. 1965, 42, 3163-3171.

[9] F. D. Lewis, T. L. Kurth, W. Z. Liu, Photochem. Photobiol. Sci. 2002, 1, 30-37.

[10] F. D. Lewis, T. L. Kurth, Can. J. Chem. 2003, 81, 770-776. 
[11] a) H. Brittain, D. L. Ambrozich, M. Saburi, J. H. Fendler, J. Am. Chem. Soc. 1980, 102, 6372-6374; b) C. D. Tran, J. H. Fendler, J. Am. Chem. Soc. 1980, 102, 29232928; c) O. Collart, K. Demeyer, S. Toppet, F. C. De Schryver, Macromolecules 1983, 16, 1390-1391; d) S. Egusa, M. Sisido, Y. Imanishi, Macromolecules 1985, 18, 882 889; e) R. Goedeweeck, M. Van Der Auweraer, F. C. De Schryver, J. Am. Chem. Soc. 1985, 107, 2334-2341; f) F. López-Arbeloa, R. Goedeweeck, F. Ruttens, F. C. De Schryver, M. Sisido, J. Am. Chem. Soc. 1987, 109, 3068-3076; g) P. Collart, F. C. De Schryver, Macromolecules 1987, 20, 1266-1271; h) N. Ikeda, H. Baba, H. Masuhara, P. Collart, F. C. De Schryver, N. Mataga, Chem. Phys. Lett. 1989, 154, 207-211.

[12] a) F. C. De Schryver, K. Demeyer, S. Toppet, Macromolecules 1983, 16, 89-94; b) M. Sisido, S. Egusa, Y. Imanishi, J. Am. Chem. Soc. 1983, 105, 1041-1049.

[13] a) U. Pischel, S. Abad, M. A. Miranda, Chem. Commun. 2003, 1088-1089; b) S. Abad, U. Pischel, M. A. Miranda, Photochem. Photobiol. Sci. 2005, 4, 69-74; c) M. A. Miranda, L. A. Martínez, A. Samadi, F. Boscá, I. M. Morera, Chem. Commun. 2002, 280-281; d) U. Pischel, S. Abad, L. R. Domingo, F. Boscá, M. A. Miranda, Angew. Chem. Int. Ed. 2003, 42, 2531-2534; e) F. Boscá, I. Andreu, I. M. Morera, A. Samadi, M. A. Miranda, J. Chem. Soc., Chem. Commun. 2003, 1592-1593.

[14] S. Abad, U. Pischel, M. A. Miranda, J. Phys. Chem. A 2005, 109, 2711-2717.

[15] I. Vayá, M. C. Jiménez, M. A. Miranda, Tetrahedron-Asymmetry 2005, 16, 21672171.

[16] For the estimation of the electron transfer driving force $\left(\Delta G_{\mathrm{et}}=E_{\mathrm{ox}}-E_{\mathrm{red}}-E^{*}+C\right)$ the following electrochemical potentials (versus SCE in DMF or acetonitrile) and excited state energy of 1-methylnaphthalene were used: $E_{\mathrm{ox}}=1.43 \mathrm{~V}, E_{\mathrm{red}}=-2.58 \mathrm{~V}$, 
$E^{*}=3.91 \mathrm{eV}, C=-0.06 \mathrm{eV}$. All data are from S. L. Murov, I. Carmichael, G. L. Hug, Handbook of Photochemistry, Marcel Dekker, New York, 1993.

[17] The intermolecular self-quenching constant of parent naphthalene has been reported as $1.8 \times 10^{8} \mathrm{M}^{-1} \mathrm{~s}^{-1}$ in $n$-hexane ( $c f$. B. Stevens, J. T. Dubois, Trans. Faraday Soc. 1966, 62, 1525-1537.).

[18] M. Takahashi, T. Odagi, H. Tomita, T. Oshikawa, M. Yamashita, Tetrahedron Lett. 2003, 44, 2455-2458.

[19] However, cycloadducts of naphthalene are rather scarcely observed and described as thermally labile. Therefore we assume that polymeric products are formed, characterized by a broad absorption spectrum extending over $330 \mathrm{~nm}$. This strongly discouraged further attempts to isolate photoproducts.

[20] HyperChem 7.5; Hypercube, Inc.: Gainsville, FL, 2002.

Received: ((will be filled in by the editorial staff))

Published online on ((will be filled in by the editorial staff)) 


\section{Figure and Scheme Legends}

Figure 1. Absorption spectra of (a) model compound (R)-1-NAP-M (full line), $(R, R)-1$ MNAP-MNAP (dotted line) and (R,S)-1-MNAP-MNAP (dashed line) and (b) (S)-NPX (full line), $(S, S)-\mathrm{NPX}-\mathrm{NPX}$ (dashed line) and $(R, S)-\mathrm{NPX}-\mathrm{NPX}$ (dotted line) in acetonitrile. The spectra of dyads have been shifted slightly upwards to avoid complete overlap.

Figure 2. Emission spectra of $(R)-1-\mathrm{NAP}-\mathrm{M}$ (solid line), $(R, R)-1-\mathrm{MNAP}-\mathrm{MNAP}$ (dashed line) and (R,S)-1-MNAP-MNAP (dotted line) in (a) acetonitrile and (b) methanol. The insets show the corresponding emission spectra (right) normalized at $321 \mathrm{~nm}$ and the excitation spectra in acetonitrile (left) for $(R, R)-1$-MNAP-MNAP at $\lambda_{\text {obs }}=321 \mathrm{~nm}$ (solid line) and $\lambda_{\text {obs }}=$ $420 \mathrm{~nm}$ (dashed line).

Figure 3. Emission spectra of (S)-NPX (full line), (S,S)-NPX-NPX (dashed line) and $(R, S)$ NPX-NPX (dotted line) in (a) $n$-hexane and (b) acetonitrile. The insets show the corresponding normalized fluorescence spectra (right) and the excitation spectra (left, for acetonitrile) of $(S, S)-\mathrm{NPX}-\mathrm{NPX}$ at $\lambda_{\mathrm{obs}}=350 \mathrm{~nm}$ (solid line) and $\lambda_{\mathrm{obs}}=430 \mathrm{~nm}$ (dashed line).

Figure 4. Normalized fluorescence decays of $(R, S)-\mathrm{NPX}-\mathrm{NPX}$ (open dots), $(S, S)$-NPX-NPX (full dots) monitored at $\lambda_{\mathrm{obs}}=430 \mathrm{~nm}$ in acetonitrile.

Figure 5. Aromatic region of the ${ }^{1} \mathrm{H}$ NMR spectra of (a) (R)-1-NAP-M, (b) (R,S)-1-MNAPMNAP and (c) $(R, R)-1-\mathrm{MNAP}-\mathrm{MNAP}$ in $\mathrm{CD}_{3} \mathrm{CN}$.

Figure 6. Aromatic region of the ${ }^{1} \mathrm{H}$ NMR spectra of (a) (S)-NPX, (b) $(S, S)-N P X-N P X$ and (c) $(R, S)-\mathrm{NPX}-\mathrm{NPX}$ in $\mathrm{CD}_{3} \mathrm{CN}$.

Scheme 1. Fluorescence quenching pathways for $(R, R)$ - and $(R, S)-1-M N A P-M N A P:(a)$ selfquenching; (b) excimer formation. 
Table 1. Fluorescence quantum yields and lifetimes of the dyads and the model compounds

\begin{tabular}{|c|c|c|c|c|}
\hline & \multicolumn{2}{|c|}{$\mathrm{MeCN}$} & \multicolumn{2}{|c|}{ n-hexane } \\
\hline & $\Phi_{\mathrm{f}}$ & $\tau_{\mathrm{f}} / \mathrm{ns}$ & $\Phi_{\mathrm{f}}$ & $\tau_{\mathrm{f}} / \mathrm{ns}$ \\
\hline$(R)-1-\mathrm{NAP}-\mathrm{M}$ & $0.22(0.17)^{[\mathrm{a}]}$ & $51.3^{[\mathrm{b}]}$ & 0.18 & $52.1^{[\mathrm{b}]}$ \\
\hline$(R, R)-1$-NAP-NAP & $0.22^{[\mathrm{a}]}$ & $51.4^{[\mathrm{b}]}$ & $---[c]$ & $---[c]$ \\
\hline$(R, S)-1-N A P-N A P$ & $0.21^{[\mathrm{a}]}$ & $49.7^{[\mathrm{b}]}$ & $---[c]$ & $---[c]$ \\
\hline$(R, R)-1-\mathrm{MNAP}-\mathrm{NAP}$ & $0.20^{[\mathrm{a}]}$ & $44.0^{[b]}$ & 0.19 & $54.3^{[\mathrm{b}]}$ \\
\hline$(R, S)-1$-MNAP-NAP & $0.20^{[\mathrm{a}]}$ & $44.7^{[\mathrm{b}]}$ & 0.18 & $51.8^{[\mathrm{b}]}$ \\
\hline$(R, R)-1$-MNAP-MNAP & $0.02(0.11)^{[\mathrm{a}]}$ & $3.3(28.9)^{[b]}$ & 0.15 & $43.4^{[\mathrm{b}]}$ \\
\hline$(R, S)-1-M N A P-M N A P$ & $0.01(0.06)^{[a]}$ & $2.2(20.6)^{[b]}$ & 0.15 & $43.8^{[\mathrm{b}]}$ \\
\hline (S)-2-NAP-M & $0.18^{[\mathrm{a}]}$ & $53.6^{[\mathrm{b}]}$ & 0.17 & $55.1^{[\mathrm{b}]}$ \\
\hline$(S, S)-2-N A P-N A P$ & $0.18^{[\mathrm{a}]}$ & $49.0^{[\mathrm{b}]}$ & $---[c]$ & $---[c]$ \\
\hline$(S, R)-2-\mathrm{NAP}-\mathrm{NAP}$ & $0.18^{[\mathrm{a}]}$ & $50.3^{[b]}$ & $---[c]$ & $---[c]$ \\
\hline$(S)-\mathrm{NPX}$ & 0.21 & 11.8 & 0.26 & 14.5 \\
\hline$(S, S)-N P X-N P X$ & $0.06^{[\mathrm{d}]}$ & $1.3(30 \%)^{[\mathrm{e}]}$ & $0.03^{[\mathrm{d}]}$ & $1.4(94 \%)^{[\mathrm{e}]}$ \\
\hline$(R, S)-N P X-N P X$ & $0.06^{[\mathrm{d}]}$ & $1.4(34 \%)^{[\mathrm{e}]}$ & $0.03^{[\mathrm{d}]}$ & $1.4(95 \%)^{[\mathrm{e}]}$ \\
\hline
\end{tabular}

[a] Fluorescence quantum yields determined under nitrogen, measured with (S)-naproxen as standard ( $\Phi_{\mathrm{f}}=0.47$ under nitrogen in acetonitrile, $c f$. ref. $\left.{ }^{[14]}\right)$. In parentheses the fluorescence quantum yields in deaerated methanol solution are given.

[b] Fluorescence lifetimes measured at $\lambda_{\mathrm{obs}}=325 \mathrm{~nm}$ under nitrogen. The fluorescence lifetimes measured in deaereated methanol solution are given in parentheses.

[c] Not measured due to low solubility of the compound in $n$-hexane.

[d] Fluorescence quantum yields in nitrogen-purged solutions, measured with $(S)$-naproxen as standard $\left(\Phi_{\mathrm{f}}=0.47\right.$ under nitrogen in acetonitrile, $c f$. ref. $\left.{ }^{[14]}\right)$.

[e] Fluorescence lifetime of the monomers measured at $\lambda_{\mathrm{obs}}=330 \mathrm{~nm}$ in nitrogen-purged solutions; the decays were fitting with bi-exponential functions. In parentheses the weighting (in \%) of the lifetime is shown. 


Tas,cis $\left(\mathrm{C}_{2}\right)$


Suggestion for the table-of-contents entry:

Diastereomeric differentiation of the fluorescence emission and excimer formation in naphthalene chromophore containing dyads was observed. The results are rationalized by invoking two excited state deactivation pathways, i.e. self-quenching and excimer formation. The latter requires ground state pre-organization of the two chromophores as verified by a correlation of NMR and fluorescence data.

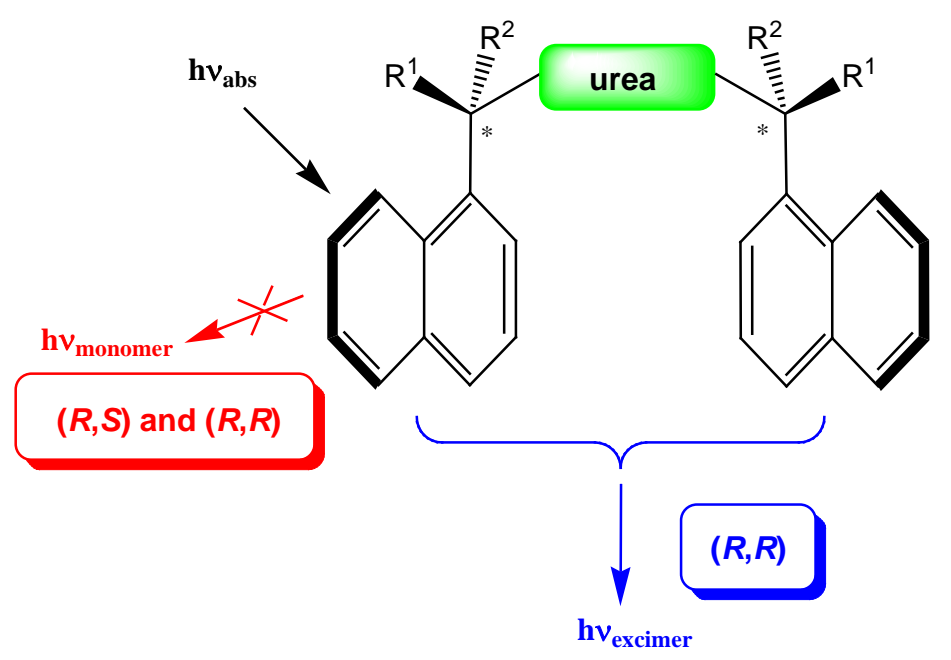




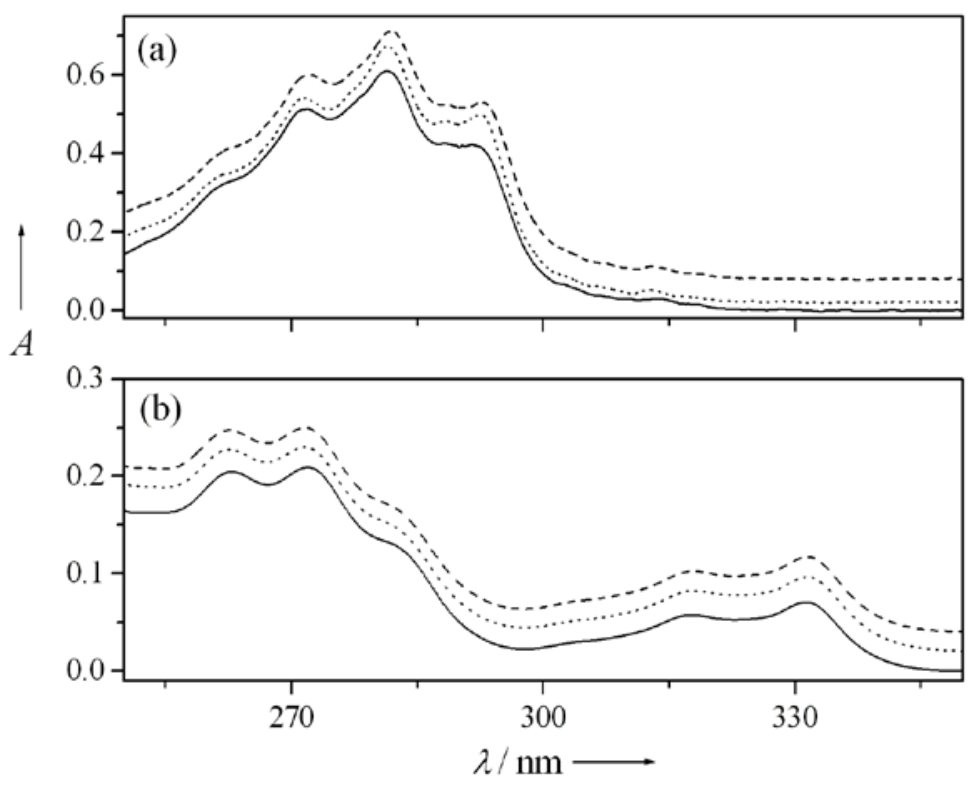

Figure 1

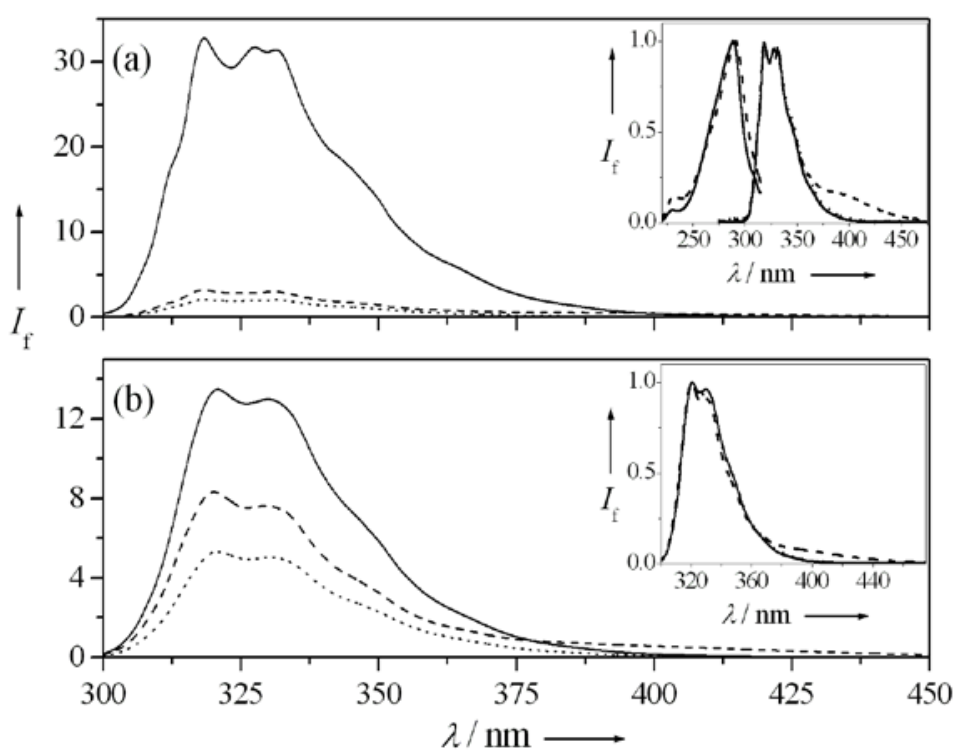

Figure 2 


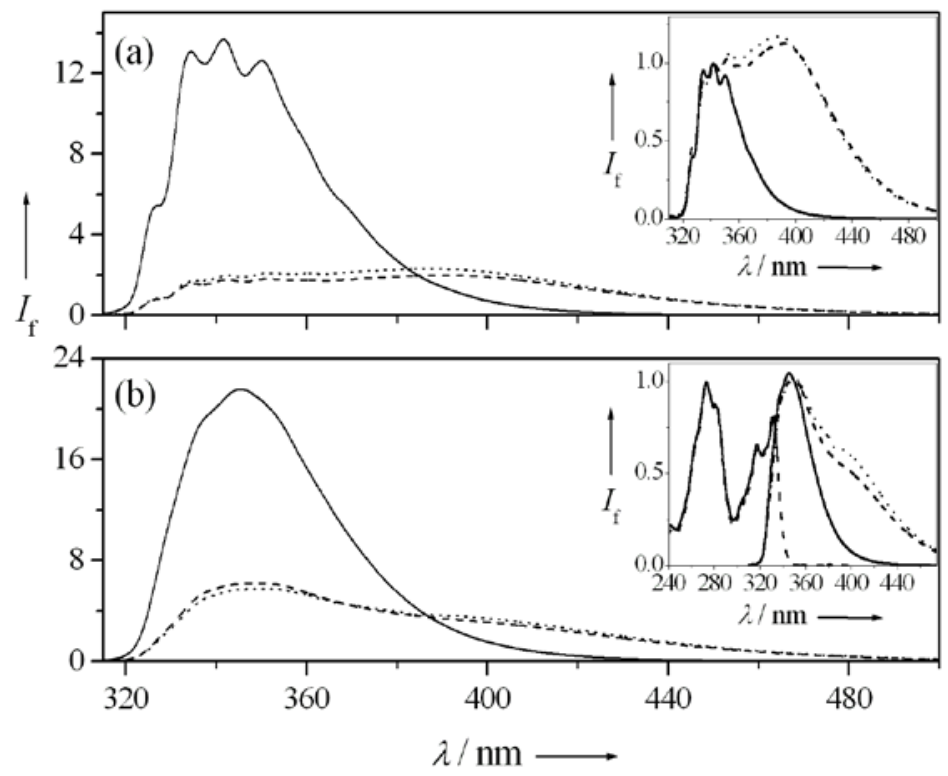

Figure 3

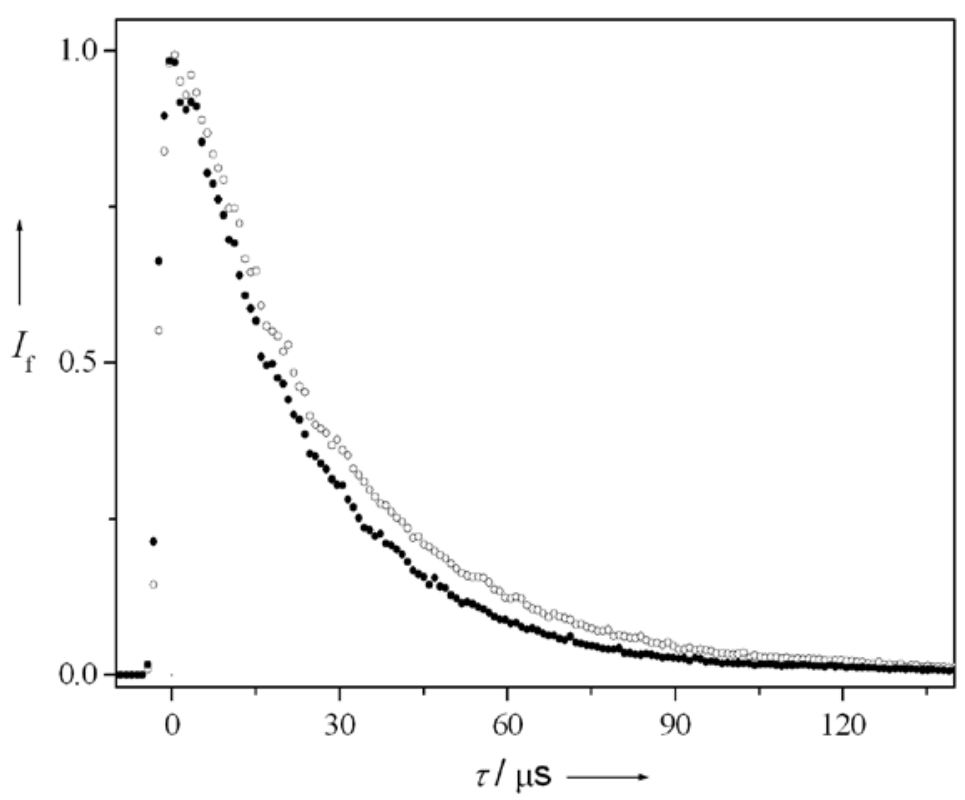

Figure 4 


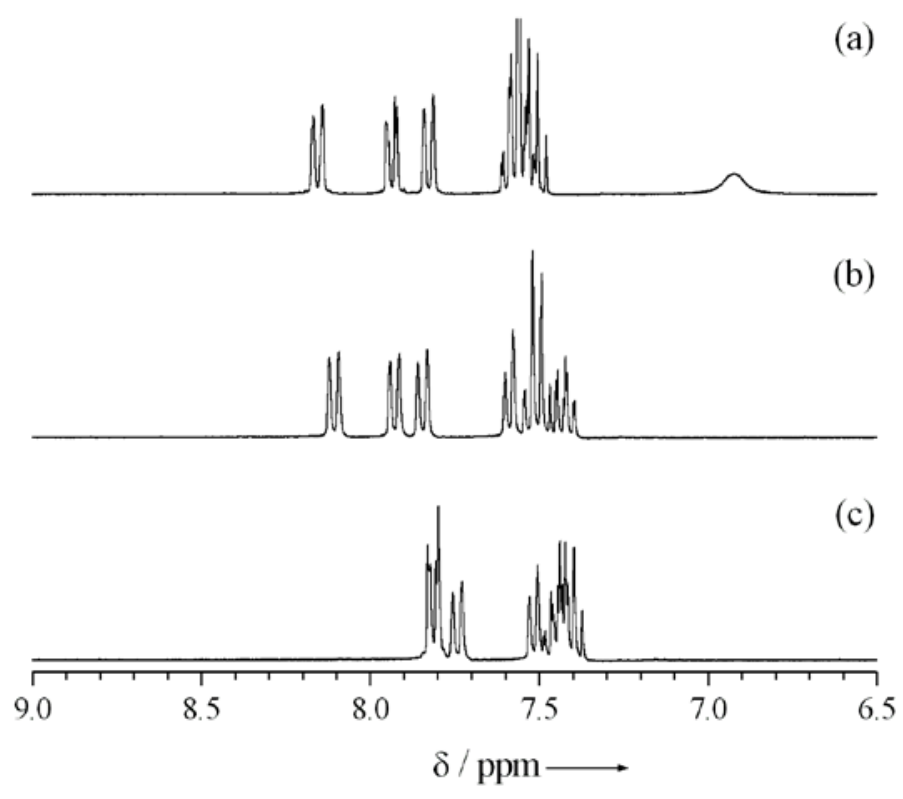

Figure 5

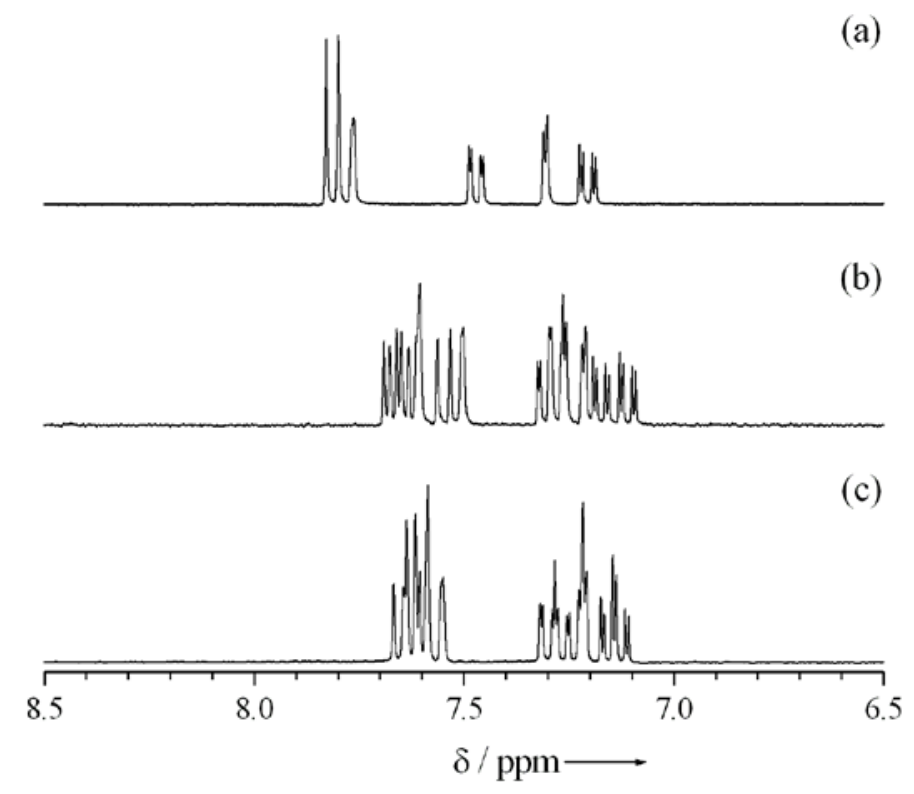

Figure 6 
<smiles>[R]N(C(=O)N([R])C([R1])([R])c1cccc2ccccc12)[C@H](C)c1cccc2ccccc12</smiles>

\begin{tabular}{c|c|c|c|} 
& $\mathrm{R}^{1}$ & $\mathrm{R}^{2}$ & $\mathrm{R}^{3}$ \\
\hline$(R, R)-1-N A P-N A P$ & $\mathrm{CH}_{3}$ & $\mathrm{H}$ & $\mathrm{H}, \mathrm{H}$ \\
$(R, S)-1-N A P-N A P$ & $\mathrm{H}$ & $\mathrm{CH}_{3}$ & $\mathrm{H}, \mathrm{H}$ \\
$(R, R)-1-M N A P-N A P$ & $\mathrm{CH}_{3}$ & $\mathrm{H}$ & $\mathrm{CH}_{3}, \mathrm{H}$ \\
$(R, S) /(S, R)-1-M N A P-N A P$ & $\mathrm{H}$ & $\mathrm{CH}_{3}$ & $\mathrm{CH}_{3}, \mathrm{H}$ \\
$(R, R)-1-M N A P-M N A P$ & $\mathrm{CH}_{3}$ & $\mathrm{H}$ & $\mathrm{CH}_{3}, \mathrm{CH}_{3}$ \\
$(R, S)-1-M N A P-M N A P$ & $\mathrm{H}$ & $\mathrm{CH}_{3}$ & $\mathrm{CH}_{3}, \mathrm{CH}_{3}$
\end{tabular}<smiles>[R]C([R])(COC(=O)[C@@H](C)c1ccc2cc(OC)ccc2c1)c1ccc2cc(OC)ccc2c1</smiles>

(S,S)-NPX-NPX

$\mathrm{R}^{1}=\mathrm{CH}_{3}, \mathrm{R}^{2}=\mathrm{H}$

$(R, S)-2-N P X-N P X$

$\mathrm{R}^{1}=\mathrm{H}, \mathrm{R}^{2}=\mathrm{CH}_{3}$<smiles>CC(=O)N[C@@H](C)c1cccc2ccccc12</smiles>

(R)-1-NAP-M<smiles>COc1ccc2cc([C@@H](C)C(=O)O)ccc2c1</smiles>

(S)-NPX

\section{Chart 1}

$(R, S)$ - and $(R, R)$-1-MNAP-MNAP<smiles>FCc1cccc2ccccc12</smiles><smiles>[R]Cc1cccc2ccc([In])cc12</smiles>

$\mathrm{R}:$<smiles>[Z]N(C)C(=O)N(C)C</smiles>

(a)

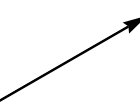

(b)

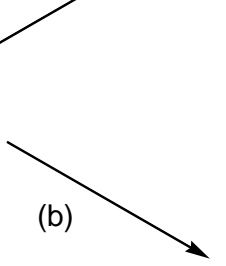

non-radiative deactivation (self-quenching) polymeric photoproducts

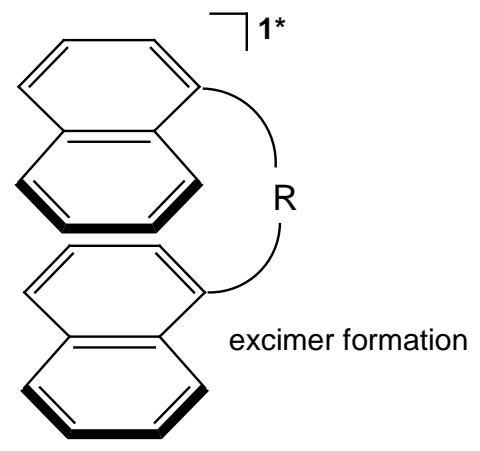

$(R, R)$-1-MNAP-MNAP

Scheme 1 